Provided for non-commercial research and education use. Not for reproduction, distribution or commercial use.

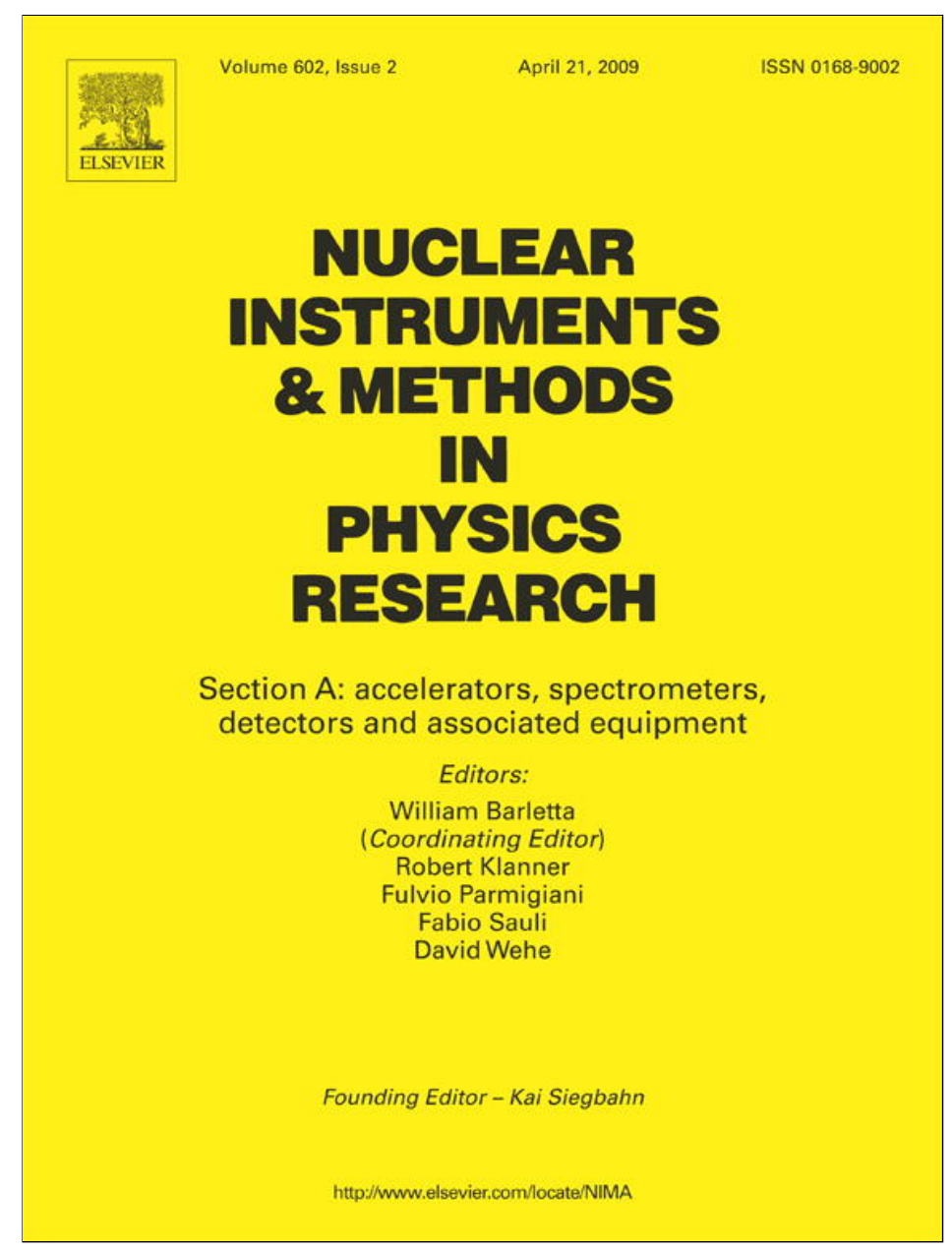

This article appeared in a journal published by Elsevier. The attached copy is furnished to the author for internal non-commercial research and education use, including for instruction at the authors institution and sharing with colleagues.

Other uses, including reproduction and distribution, or selling or licensing copies, or posting to personal, institutional or third party websites are prohibited.

In most cases authors are permitted to post their version of the article (e.g. in Word or Tex form) to their personal website or institutional repository. Authors requiring further information regarding Elsevier's archiving and manuscript policies are encouraged to visit:

http://www.elsevier.com/copyright 


\title{
Hard X-ray imaging by a spherical compound refractive lens
}

\author{
Chengchao Huang ${ }^{\mathrm{a}}$, Baozhong $\mathrm{Mu}^{\mathrm{a}}$, Zhanshan Wang ${ }^{\mathrm{a}, *}$, Lingyan Chen ${ }^{\mathrm{a}}$, Yu.I. Dudchik ${ }^{\mathrm{b}}$ \\ ${ }^{a}$ Institute of Precision Optical Engineering, Tongji University, Shanghai 200092, China \\ b Institute of Applied Physics Problems of Belarus State University, Kurchatova 7, 220064 Minsk, Belarus
}

\section{A R T I C L E I N F O}

\section{Article history:}

Received 17 September 2008

Received in revised form

12 January 2009

Accepted 18 January 2009

Available online 20 February 2009

Keywords:

X-ray optics

Compound refractive lens

$\mathrm{X}$-ray imaging

\begin{abstract}
A B S T R A C T
Hard X-ray imaging by a spherical compound refractive lens is presented. The lens is composed of 123 biconcave microlenses with a size of $200 \mu \mathrm{m}$ in diameter. Each microlens was formed by the epoxy between two bubbles, which were injected into an epoxy-filled glass capillary. The focal length of the lens is $114 \mathrm{~mm}$ at $8.05 \mathrm{keV}$. The light source was obtained by using a copper anode X-ray tube without a filter. The lens can be achieved a spatial resolution of $5 \mu \mathrm{m}$ with field of view of about $700 \mu \mathrm{m}$, and $1-3 \mu \mathrm{m}$ resolution may be obtainable by using monochromator and diaphragm.
\end{abstract}

(c) 2009 Elsevier B.V. All rights reserved.

\section{Introduction}

There is a growing demand for non-destructive hard X-ray microscopy techniques to visualize the interior of opaque samples. Fresnel zone plates [1], and reflective optics [2] such as $\mathrm{K}-\mathrm{B}$ systems, were used to form images, but these devices are generally expensive so that limit their applications in imaging systems. In addition, it is challenging to place and align them properly in practice. Almost all laboratory imaging was achieved by simple shadow casting from a microspot X-ray source. These apparatus, which are cheaper and easy to be aligned setup, can reach a resolution slightly below $1 \mu \mathrm{m}$. But their resolution is limited by the inherent resolution of the 2D detector, which is determined by the interaction of X-rays with a scintillator and the resolution of the visible light optics of the detector. Thus it is difficult to further enhancing resolution by using these types of microscopes [3]. Compound refractive lens (CRL), invented 12 years ago in European Synchrotron Radiation Facility (ESRF) [4], was used in hard X-ray collimating [5], nanofocusing [6,7] and imaging [8-11]. Due to its compact structure, flexible alignment, advanced technique of manufacture and large numbers of available materials, CRL could be used to focus hard X-rays in the range of $5-150 \mathrm{keV}[12,13]$ or to image opaque samples illuminated by monochromatic X-rays, providing the resolution about 300-500 $\mathrm{nm}[9,11]$.

A spherical compound refractive lens consists of a series of bubbles encased in an epoxy-filled glass capillary, where the epoxy between two bubbles forms a biconcave spherical lens

\footnotetext{
* Corresponding author. Tel.: +862165984652; fax: +862165984652. E-mail address: wangzs@mail.tongji.edu.cn (Z. Wang).
}

under the action of surface tension forces [14,15]. There are three advantages ensuring good image quality of the lens for using in hard X-rays: (1) The epoxy $\left(\mathrm{C}_{100} \mathrm{H}_{200} \mathrm{O}_{20} \mathrm{~N}, 1.08 \mathrm{~g} / \mathrm{cm}^{3}\right)$ is composed of carbon, hydrogen, and nitrogen, each of them is characterized by a low absorption coefficient for 5-30 keV X-rays. (2) Because of the nature of physics forming the bubble, the lens surface quality is extremely good. (3) The capillary ensures that the series of unit lenses are well aligned coaxially.

In this paper, images using an unfiltered X-ray tube and a spherical compound refractive lens were obtained, and resolution below $5 \mu \mathrm{m}$ was achieved by using this apparatus.

\section{Theory of compound refractive lens}

The refractive index for X-rays in matter can be written as

$n=1-\delta+i \beta$

where $\delta$ is the refractive index decrement (typically between $10^{-5}$ and $10^{-7}$ ) and $\beta$ is the absorption index.

As shown in Fig. 1, each biconcave lens has a focal length of $f_{1}=R / 2 \delta$. Due to the rather small refraction, the focal length is very large with a value of about $13 \mathrm{~m}$ in this lens. Based on the compound construction, a series of $N$ biconcave unit lenses can be aligned in a line to form a CRL with total focal length $f$ as:

$f=\frac{f_{1}}{N}=\frac{R}{2 N \delta}$

where $R$ is the radius of lens, which is equal to the radius of capillary [4].

Although the focal length formula is based on the thin-lens approximation, still the thickness of CRL are comparable to its 


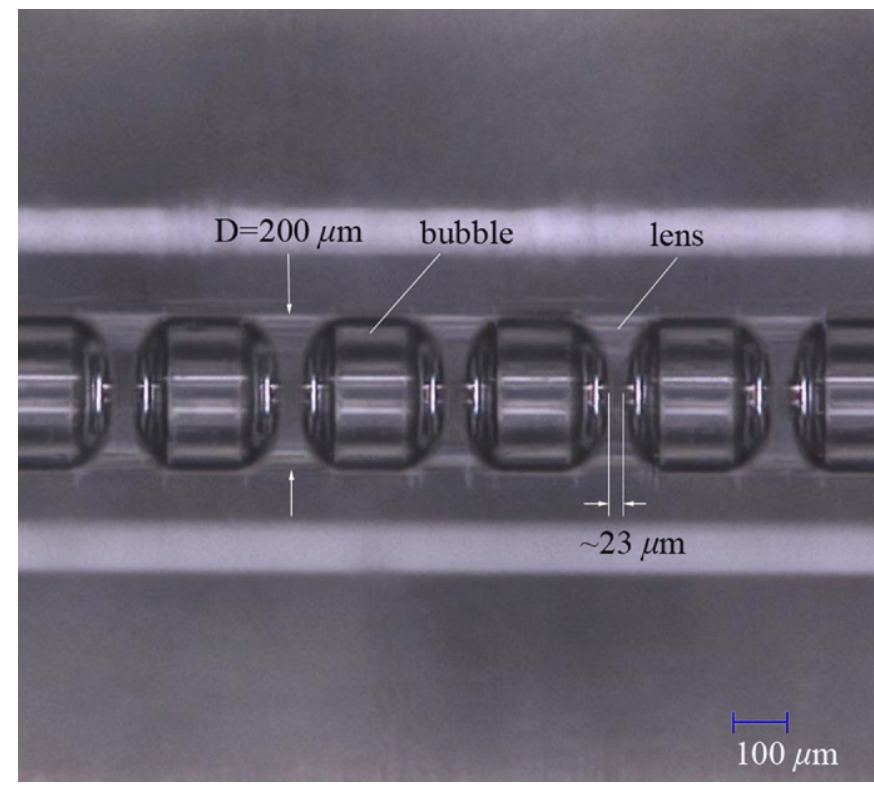

Fig. 1. Photograph of a spherical CRL inside glass capillary of $200 \mu \mathrm{m}$ internal diameter. The interface between two air bubbles has a biconcave form and acts as a lens for X-rays. The average minimum thickness between two bubbles is $23 \mu \mathrm{m}$.

focal length, thus the thick-lens analysis must be used [16]. The focal length $f_{\mathrm{t}}$ of a thick lens can be formulated as

$f_{t}=f \frac{(t / f)^{1 / 2}}{\sin (t / f)^{1 / 2}}$

where $t$ is the length of all lenses. The focal length $f_{t}$ is measured from the principal plane of image space of a lens to the focal spot. The familiar lens formula can be rewritten as

$\frac{1}{p}+\frac{1}{q}=\frac{1}{f_{t}}$

where $p$ is the distance from the object to the principal plane of object space of a thick lens, $q$ is the distance from the principal plane of image space of a thick lens to image plane (sensitive plane of the X-ray camera). The magnification is given by the ratio $M=q / p$. The distance $d$ between the lens surfaces and the principal plane can be calculated by [16]

$d=f_{t}\left[1-\cos \left(\frac{t}{f}\right)^{1 / 2}\right]$

Due to the high absorption at the edges of the lens, the geometrical aperture is much larger than the effective aperture $D_{\text {eff, }}$, which is defined as the opening diameter where the image intensity has decreased to $e^{-2}$ of its peak value.

$D_{\text {eff }}=4\left(\frac{\delta f_{t}}{\mu}\right)^{1 / 2}$

where $\mu$ is the linear absorption coefficient of lens material [4]. The effective aperture $D_{\text {eff }}$ can be used to determine some important parameters of the lens such as the field of view (FOV), which can be expressed as [10]

$F O V=\frac{2 D_{e f f} p}{t}$

\section{Expected resolution}

The spherical CRL is composed of 123-unit spherical and biconcave microlenses, and each of the microlenses can be deemed as an optical element with the curvature radius of $100 \mu \mathrm{m}$ in this experiment. The total length of the lens $t$ is $41 \mathrm{~mm}$. The spherical CRL was fabricated by injecting air bubbles into the epoxy-filled capillary one by one [17]. For $8.05 \mathrm{keV}$ monochromatic X-rays, the refractive index decrement $\delta$ is $3.781 \times 10^{-6}$ calculated by the formula of $\delta=0.5(22 / E)^{2}$, where $E$ is photon energy measured in electron volts [18]. The linear absorption coefficient of lens material $\mu$ of the epoxy is $5.8 \mathrm{~cm}^{-1}$ in this experiment. The focal length $f_{t}$, according to Eq. (3), is $114 \mathrm{~mm}$. The effective aperture $D_{\text {eff }}$ is equal to $109 \mu \mathrm{m}$. The distance $d$ from the lens surfaces to the principal plane is $21 \mathrm{~mm}$. The distance between the center of the lens and the lens surfaces is $20.5 \mathrm{~mm}$, and the principal plane is $0.5 \mathrm{~mm}$ away from the center of the lens.

The imaging was simulated by the commercial program of ZEMAX [19]. The optical model was built exactly the same as the design. Considering the source was an unfiltered X-ray tube, polychromatic light was used, which consisted of 7, 8.05 and $8.98 \mathrm{keV}$ X-rays. Mesh \#1500 ( $5.5 \mu \mathrm{m}$ wires separated by $16.5 \mu \mathrm{m})$ was set as object and was placed at a distance of $p=133 \mathrm{~mm}$ from the principal plane of object space of the lens. The image plane was put at $q=798 \mathrm{~mm}$ behind the principal plane of image space of the lens with a magnification of $M=6$. Geometric image analysis and MTF were performed. As can be seen in Fig. 2, the image was not satisfactory when light source is

a

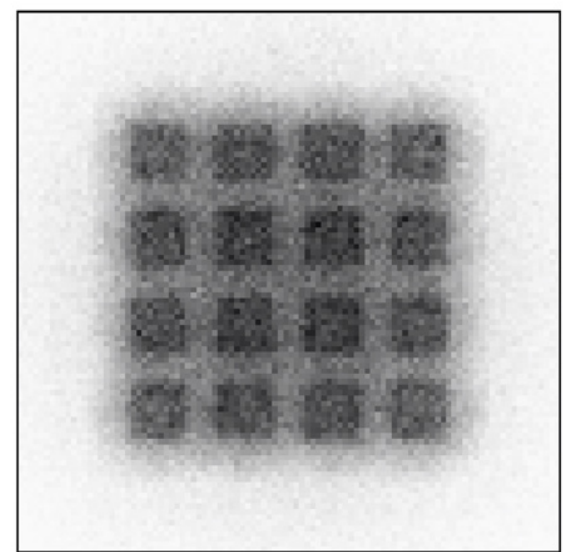

2.5358

2.2822

2.0287

1.7751

1.5215

1.2679

1.0143

$0.760 ?$

๑. 5072

0.2536

Image width $=0.645 \mathrm{~mm}, 100 \times 100$ pixels

0.0000

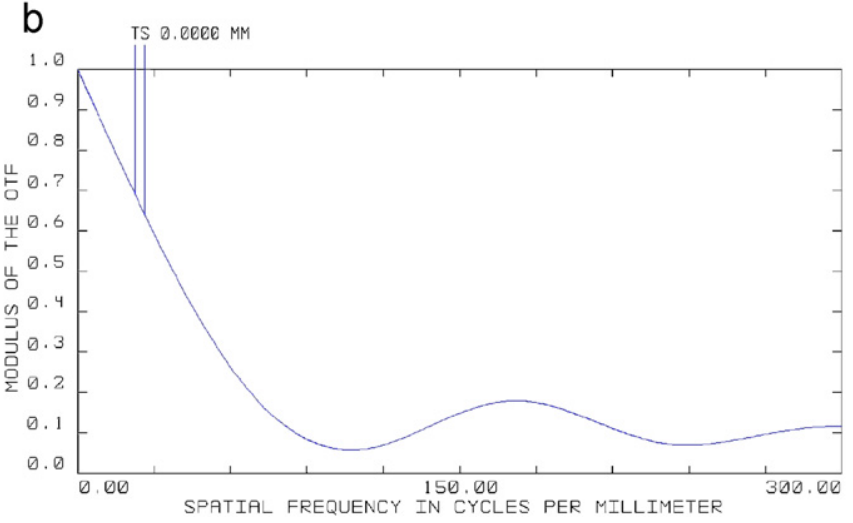

Fig. 2. Results of imaging simulation. (a) Geometric image analysis. A mesh \# 1500 $(5.5 \mu \mathrm{m}$ wires separated by $16.5 \mu \mathrm{m})$ was set as object. Simulation result was shown in 256 grey scale levels. Each pixel size is $6.45 \times 6.45 \mu \mathrm{m}^{2}$, just same as the parameters of the detector; (b) MTF's for the simple X-ray imaging apparatus with polychromatic light (7, 8.05 and $8.98 \mathrm{keV}$ X-rays) and a spherical compound refractive lens as optical element. The spatial frequency was 56 cycles $/ \mathrm{mm}$ with $30 \%$ contrast, which means the resolution was about $9 \mu \mathrm{m}$. 


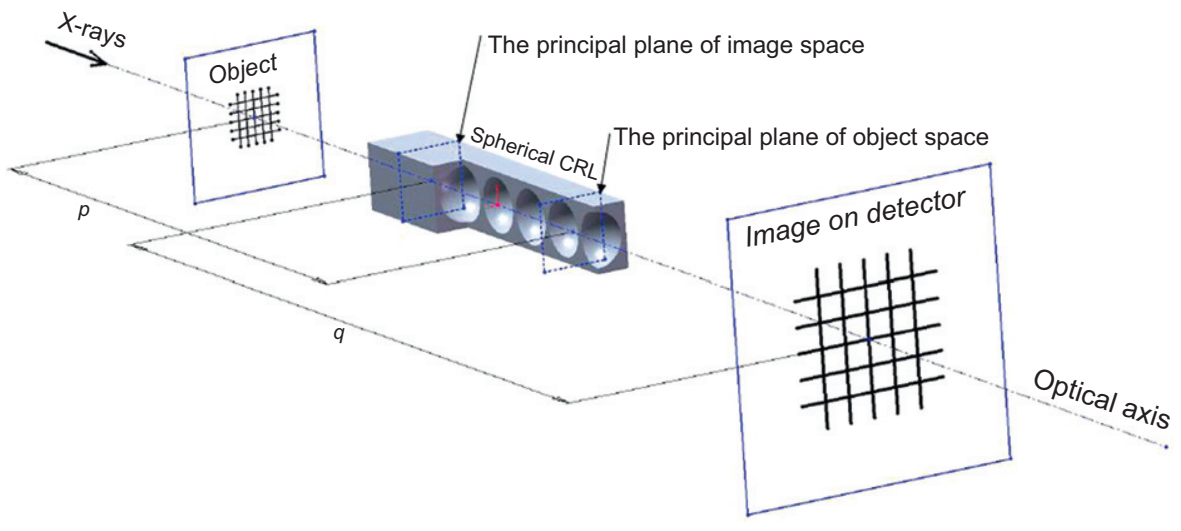

Fig. 3. Schematic diagram of the simple X-ray imaging apparatus.

polychromatic, and spatial frequency was 56 cycles $/ \mathrm{mm}$ with a contrast of $30 \%$, which means that the resolution is $9 \mu \mathrm{m}$ approximately.

\section{Experimental results}

The experimental setup of the resolution of CRL is composed of three main components: an X-ray tube, a spherical CRL, and an $\mathrm{X}$-ray detector. The schematic diagram of the optical system was shown in Fig. 3. The X-ray tube in the experiment was a homemade X-ray tube with a $\mathrm{Cu}$ anode and an apparent source with an area of $0.4 \times 0.4 \mathrm{~mm}^{2}$. The tube voltage was set to $21 \mathrm{kV}$ and the current was $10 \mathrm{~mA}$, which was caused by a standard bremsstrahlung and $8 \mathrm{keV}$ characteristic-line spectra from the tube without filtering. The detector was a Peltier-cooled, $1380 \times 1030$ format $\left(6.45 \times 6.45 \mu \mathrm{m}^{2}\right.$ pixels $)$ charge-coupled device with a fiber-optic-coupled scintillator (Photonic Sciences Ltd., "X-ray Fast Digital Imager") [20].

Image of mesh was processed to subtract out the background without mesh. The processed image of mesh $I^{\prime}$ was obtained by $I^{\prime}=I-K I_{0}$, where $I_{0}$ is the image of the source without the mesh, $I$ is the image of the mesh, and $K$ is a variable constant, which can be changed so as to meet the best contrast $(K=0.6)$.

Two gold meshes were used as the objects: gold mesh \#600 ( $7.7 \mu \mathrm{m}$ wires separated by $41.4 \mu \mathrm{m})$ and gold mesh \#1500 $(5.5 \mu \mathrm{m}$ wires separated by $16.5 \mu \mathrm{m})$. The images were shown in Figs. 4 and 5. Gold mesh \#600 was put in the place where there is $152 \mathrm{~mm}$ away from the principal plane of object space of the lens, and a $3 \times$ image was formed in the place $452 \mathrm{~mm}$ behind the principal plane of image space of the lens. The FOV is $808 \mu \mathrm{m}$. Gold mesh \#1500 and X-ray detector was put exactly the same as the parameters in the simulation $(p=133 \mathrm{~mm}, q=798 \mathrm{~mm})$ with a magnification of $M=6$. The FOV is $707 \mu \mathrm{m}$.

As shown in Fig. 4, gold wires with the size of $7.7 \mu \mathrm{m}$ were imaged with good contrast. As can be seen in Fig. 5, gold wires with the size of $5.5 \mu \mathrm{m}$ can be recognized by the digital camera, which means that the spatial resolution of the simple X-ray imaging apparatus will not worse than $5.5 \mu \mathrm{m}$. Because the image-processing techniques are helpful to the contrast of image, the resolution of the apparatus can be better than the simulated resolution of $9 \mu \mathrm{m}$. Better resolution will not be achievable for the given experimental conditions unless monochromator and diaphragm are used. As shown in Fig. 6, contrast with the value of $30 \%$ can be obtained at higher spatial frequency of $281 \mathrm{cycles} / \mathrm{mm}$, that is, resolution of $1.8 \mu \mathrm{m}$, can be achieved using monochro-

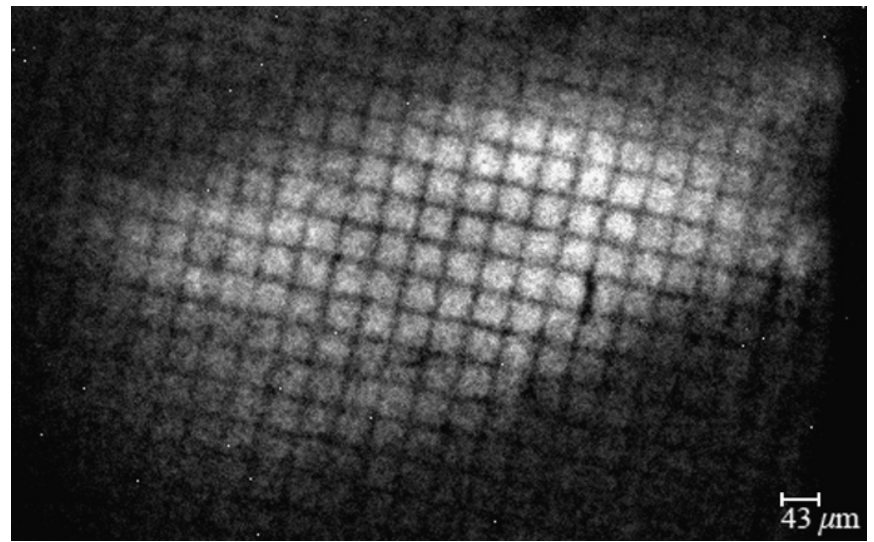

Fig. 4. A $3 \times$ image of gold mesh \#600 ( $7.7 \mu \mathrm{m}$ wires separated by $41.4 \mu \mathrm{m})$, at $210 \mathrm{~W}$ for $30 \mathrm{~min}$. The image was cut from the whole image whose FOV was about $800 \mu \mathrm{m}$. The non-circular shape of illuminated area was determined by the shape of the source. The blur on the right side of the image was caused by the fault of scintillator in the detector.

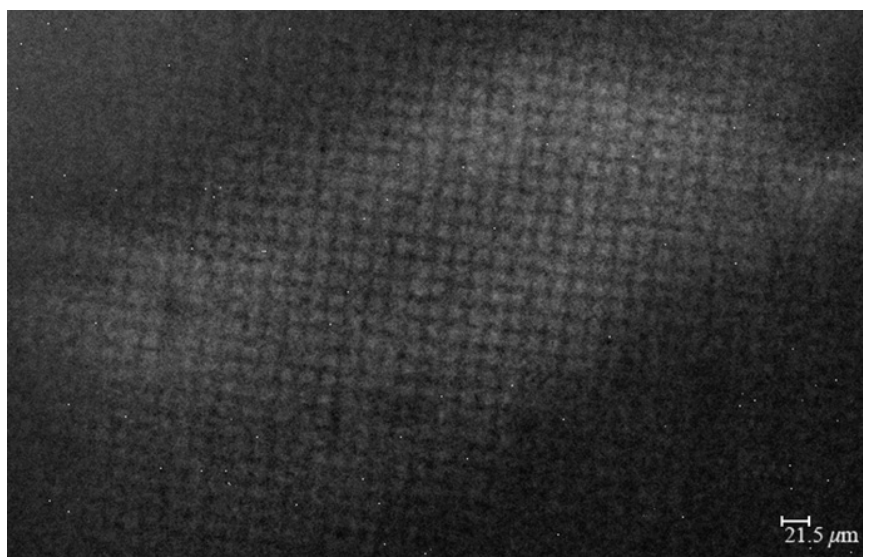

Fig. 5. A $6 \times$ image of gold mesh \#1500 (5.5 $\mu \mathrm{m}$ wires separated by $16.5 \mu \mathrm{m})$, at $210 \mathrm{~W}$ for $45 \mathrm{~min}$. The image was cut from the whole image whose FOV was about $700 \mu \mathrm{m}$. The non-circular shape of illuminated area was determined by the shape of the source.

mator for $8.05 \mathrm{keV}$ photon energy. For higher spatial frequency of 1530 cycles/mm with the contrast of $30 \%$, resolution of $327 \mathrm{~nm}$ may be obtained by combining monochromator for $8.05 \mathrm{keV}$ and $50 \mu \mathrm{m}$ diameter diaphragm at the front of the lens. 

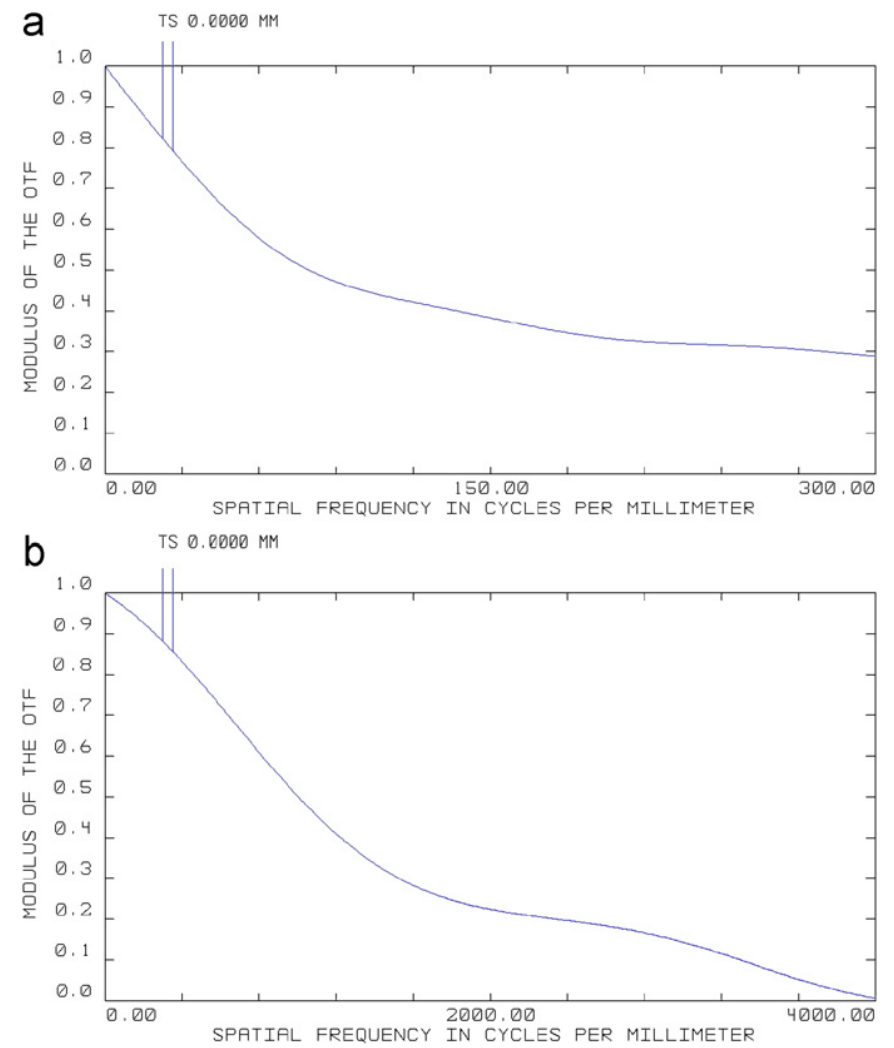

Fig. 6. MTF's for the simple X-ray imaging apparatus with a spherical compound refractive lens and monochromator or both monochromator and diaphragm. (a) Using monochromator for $8.05 \mathrm{keV}$. The spatial frequency was $281 \mathrm{cycles} / \mathrm{mm}$ at $30 \%$ contrast, $1.8 \mu \mathrm{m}$ resolution in another word; (b) Using both monochromator for $8.05 \mathrm{keV}$ and $50 \mu \mathrm{m}$ diameter diaphragm. The spatial frequency was 1530 cycles $/ \mathrm{mm}$ at $30 \%$ contrast, which means resolution of $327 \mathrm{~nm}$.

\section{Conclusion}

Imaging experiment shows that the spherical compound refractive lens may be a promising imaging optical element for hard X-rays with a resolution better than $5 \mu \mathrm{m}$. Resolution of CRL can be enhanced by using monochromator and diaphragm.

\section{Acknowledgements}

This work was supported by National Natural Science Foundation of China (Grant no. 10575076), by National 863 Program and by the Shanghai Committee of Science and Technology, China (Grant no. 07DZ22302 and 08520704100).

\section{References}

[1] J. Thieme, S. Gleber, G. Mitrea, P. Guttmann, Opt. Precision Eng. 15 (2007) 1878.

[2] Z.S. Wang, X.D. Chen, Opt. Precision Eng. 7 (1999) 1.

[3] A. Koch, C. Raven, P. Spanne, A. Snigirev, J. Opt. Soc. Am. A 15 (1998) 1940.

[4] A. Snigirev, V. Kohn, I. Snigireva, B. Lengeler, Nature (London) 384 (1996) 49.

[5] I. Snigireva, M. Grigoriev, L. Shabel'nikov, V. Yunkin, A. Snigirev, S. Kuznetsov, M. Di Michiel, M. Hoffmann, E. Voges, Proc. SPIE 4783 (2002) 19.

[6] C.G. Schroer, O. Kurapova, J. Patommel, Appl. Phys. Lett. 87 (2005) 124103.

[7] Yu.I. Dudchik, N.N. Kolchevsky, F.F. Komarov, M.A. Piestrup, J.T. Cremer, C.K. Gary, H. Park, A.M. Khounsary, Rev. Sci. Instrum. 75 (2004) 4651.

[8] C.K. Gary, S.A. Pikuz, M.D. Mitchell, K.M. Chandler, T.A. Shelkovenko, D.A. Hammer, Yu.I. Dudchik, Rev. Sci. Instrum. 75 (2004) 3950.

[9] B. Lengeler, C.G. Schroer, M. Richwin, J. Tümmler, M. Drakopoulos, A. Snigirev, I. Snigireva, Appl. Phys. Lett 74 (1999) 3924

[10] M.A. Piestrup, C.K. Gary, H. Park, J.L. Harris, J.T. Cremer, R.H. Pantell, Y.I. Dudchik, N.N. Kolchevsky, F.F. Komarov, Appl. Phys. Lett. 86 (2005) 131104

[11] C.G. Schroer, T.F. Günzler, B. Benner, M. Kuhlmann, J. Tümmler, B. Lengeler, C. Rau, T. Weitkamp, A. Snigirev, I. Snigireva, Nucl. Instr. and Meth. A 467-468 (2001) 966 .

[12] I. Snigireva, A. Snigirev, J. Environ. Monit. 8 (2006) 33.

[13] A. Snigirev, I. Snigireva, M. Di Michiel, V. Honkimaki, M. Grigoriev, V. Nazmov, E. Reznikova, J. Mohr, V. Saile, Proc. SPIE 5539 (2004) 244.

[14] Yu.I. Dudchik, N.N. Kolchevsky, Nucl. Instr. and Meth. A 421 (1999) 361.

[15] Yu.I. Dudchik, N.N. Kolchevsky, F.F. Komarov, Proc. SPIE 4765 (2002) 26.

[16] R.H. Pantell, J. Feinstein, H.R. Beguiristain, M.A. Piestrup, C.K. Gary, J.T. Cremer, Appl. Opt. 42 (2003) 719.

[17] Yu.I. Dudchik, N.N. Kolchevsky, F.F. Komarov, Y. Kohmura, M. Awaji, Y. Suzuki, T. Ishikava, Nucl. Instr. and Meth. A 454 (2000) 512.

[18] Yu.I. Dudchik, C.K. Gary, H. Park, R.H. Pantell, M.A. Piestrup, Proc. SPIE 6705 (2007) 670509.

[19] 〈http://www.zemax.com/ >.

[20] 〈http://www.photonic-science.co.uk/ $\rangle$. 